\title{
Eco-friendly synthesis of silver nanoparticles using leaf extract of Flemingia wightiana: spectral characterization, antioxidant and anticancer activity studies
}

\author{
Netala Vasudeva Reddy ${ }^{1}$. Bethu Murali Satyanarayana ${ }^{2}$. Sana Sivasankar ${ }^{3}$. Duggina Pragathi ${ }^{1}$. \\ Kotakadi Venkata Subbaiah ${ }^{4} \cdot$ Tartte Vijaya $^{5}$
}

Received: 12 December 2019 / Accepted: 6 April 2020 / Published online: 11 April 2020

(c) Springer Nature Switzerland AG 2020

\begin{abstract}
In the present investigation, we report simple, robust and eco-friendly synthesis of silver nanoparticles (AgNPs) using leaf extract of Flemingia wightiana. The leaf extract of $F$. wightiana acts as reducing agent which reduces the silver ions into FW-AgNPs, as well as stabilizing agent by capping around them. Biosynthesized FW-AgNPs were characterized by different spectroscopic techniques. UV-Vis spectrum showed the characteristic SPR peak between 380 and $460 \mathrm{~nm}$. EDX analysis revealed the presence of metallic silver at $3 \mathrm{keV}$. XRD analysis clearly revealed that FW-AgNPs are crystalline in nature with FCC structure. TEM analysis depicted the spherical morphology with 20-40 nm in size. DLS analysis showed that average hydrodynamic size and PDI value of FW-AgNPs were found to be $47.6 \mathrm{~nm}$ and 4.5 respectively. Biosynthesized FW-AgNPs showed high negative zeta potential value of $-25.3 \mathrm{mV}$. FTIR analysis revealed the participation of polyphenols and proteins in the bioreduction and stabilization of FW-AgNPs. FW-AgNPs showed strong DPPH and $\mathrm{H}_{2} \mathrm{O}_{2}$ scavenging activity with IC50 values of 71.96 and $80.59 \mu \mathrm{g} / \mathrm{mL}$ respectively. Further FW-AgNPs also showed effective cytotoxicity against cancer cells including SKOV3 and COLO205 with maximum inhibition of $83.2 \%$ and $75.9 \%$ respectively.
\end{abstract}

Keywords Flemingia wightiana $\cdot$ Silver nanoparticles $\cdot$ Antioxidant activity $\cdot$ Cytotoxicity $\cdot$ SKOV3 $\cdot$ COLO205

\section{Introduction}

Metallic nanoparticles possess unique physico-chemical properties such as optical, electronic, thermal and catalytic properties due to their small size, large surface area-volume ratio, and spatial confinement [1]. Due to their unique physico-chemical properties, metallic nanoparticles particularly silver nanoparticles (AgNPs) have attracted more attention in the field of nanomedicine. AgNPs have been widely employed in the theranostics, particularly drug delivery and bioimaging [2]. AgNPs have been employed in the treatment of cardiovascular diseases, neurodegenerative diseases, brain inflammation, neurotoxicity and diabetes etc. [3-5]. AgNPs have been widely used as antifilarial, antiinsecticidal, antilarvicidal, antiprotozoal and anticandidal agents [6-9]. Due to their characteristic surface plasmon resonance (SPR) phenomenon, AgNPs have been used particularly in the preparation of fluorescent sensors. These sensors could be used for the detection of pathogenic bacteria, fungi and virus of animal and crop diseases [10-12]. AgNPs have been widely employed as optical probes for SERS and MEF. (Surface-enhanced

Netala Vasudeva Reddy and Bethu Murali Satyanarayana have contributed equally to this work.

$\square$ Netala Vasudeva Reddy, vasubioteck07@gmail.com; $₫$ Tartte Vijaya, tvijayasvu@yahoo.com | ${ }^{1}$ Department of Biotechnology, Sri Venkateswara University, Tirupati, Andhra Pradesh, India. ${ }^{2}$ Biology and Toxicology Division, CSIR-IICT, Hyderabad, Telangana, India. ${ }^{3}$ Department of Chemistry, Yogivemana University, Kadapa, Andhra Pradesh, India. ${ }^{4}$ DST-PURSE Center, Sri Venkateswara University, Tirupati, Andhra Pradesh, India. ${ }^{5}$ Department of Botany, Sri Venkateswara University, Tirupati, Andhra Pradesh, India. 
Raman scattering and metal-enhanced fluorescence). AgNPs shows more advantages such as sharp extinction bands, high extinction coefficients and field enhancements for probes $[13,14]$. AgNPs have been successfully employed for the catalytic degradation of dyes and pollutants $[15,16]$. AgNPs successfully employed as green and robust catalysts in different chemical reactions involving catalysis and organic transformations $[17,18]$. AgNPs have been widely employed in textile industries due to their antimicrobial efficacies which impart powerful anti-odor abilities to the clothes [19]. Due to their antistatic abilities AgNPs have been especially added in the preparation of synthetic fabrics such as polyesters [20]. Due to their innate antimicrobial nature, AgNPs have been used successfully in the coatings and paintings of construction industry, mostly hospital walls, woods, glass, and countertops to reduce the growth of fungi and bacteria on the building walls especially in winter and rainy seasons [21]. AgNPs have been widely used for in vitro engineered tissue vascular grafts. The innate antimicrobial properties of AgNPs enabled them for infusion into grafting materials including hydroxyapatite, polycaprolactone, poly(l-lactide-co-capro lactone), alginate and collagen [22]. Owing to their antimicrobial nature, AgNPs have been used particularly in the preparation of food packaging materials, wound dressings, and medical equipments. The market of AgNPs have been increased year to year due to their vast usage in the industries related to food packaging, wound dressings, diagnostic kits and other medical equipments [23-25]. Different chemical and physical methods including thermal decomposition [26], laser ablation [27], electrochemical [28], photochemical [29], sonochemical [30], gamma-irradiated [31], ultrasound assisted [32], polyaniline [33], chemical reduction [34], and lithography [35] methods have been successfully reported for the preparation of AgNPs. But these methods employ radiations and toxic chemicals. In these methods capping of AgNPs need further processes and chemicals. Toxic radiations and chemicals limit the application of AgNPs in biomedicine, clinical and pharmaceutical fields. Further their biocompatibility is also remains in question sometimes. Hence the preparation of AgNPs using biological methods grabs the attention of researchers around the world. Preparation of AgNPs using biological methods has advantages over chemical and physical methods. Biological synthesis methods are simple, rapid and easy methods. Biological synthesis methods produced non toxic and biocompatible AgNPs. Biological methods involve simple bioreduction methods and need not separate capping processes and separate capping agents. AgNPs have been prepared using different plant extracts including Gymnema sylvestre [36], Centella asiatica [37], Melia dubia [38], Rhynchosia suaveolens [39], Shorea roxburghii [40], Morus alba [41],
Priva cordifolia [42], Catharanthus roseus [43], Andrographis paniculata [44], Cordia dichotoma [45], Cassia angustifolia [46], Amaranthus cruentus [47], Cola nitida [48], Arnebia hispidissima [49], Petiveria alliacea [50], Persea Americana [51], Buchanania axillaris [52], and Jatropha curcas [53] etc.

The plant Flemingia wightiana Wight\&Arn is belongs to the legume family. The plant is classified as Kingdom: Plantae, Phylum: Tracheophyta, Class: Magnoliopsida, Order: Fabales, Family: Fabaceae, subfamily: Faboideae, Genus: Flemingia, Species: wightiana. The plant is widely distributed in the Asian countries including India, China, Pakistan, Burma, Bhutan, Indonesia and Sri Lanka [54] The Whole plant extracts of $F$. wightiana possess antimicrobial, antioxidant, antidiabetic, and antiinflammatory activities [55]. In the present study we have investigated the biosynthesis of AgNPs using leaf extract of $F$. wightiana. The synthesized FW-AgNPs were characterized using different spectroscopic techniques including ultraviolet-visible (UV-Vis), Fourier transform infrared (FTIR), Energy dispersive X-ray spectroscopy (EDX), X-ray diffraction (XRD), transmission electron microscope (TEM) and dynamic light scattering (DLS). Further the biosynthesized FW-AgNPs were evaluated for antioxidant activity by DPPH and $\mathrm{H}_{2} \mathrm{O}_{2}$ free radical scavenging assays. FW-AgNPs were evaluated for cytotoxicity against human ovarian carcinoma (SKOV3) and human colon carcinoma (COLO205) cell lines.

\section{Materials and methods}

\subsection{Chemicals}

Silver nitrate $\left(\mathrm{AgNO}_{3}\right)$ was purchased from Molychem, India. All the materials and chemicals required for antioxidant and cytotoxicity studies were purchased from Himedia and Sigma-Aldrich, India.

\subsection{Collection of plant material}

The plant material of $F$. wightiana was collected from Talakona region, Seshachalam hills, Eastern Ghats, Andhra Pradesh, India. The plant material was authenticated by Taxonomist, Department of Botany, Sri Venkateswara University, and Andhra Pradesh, India.

\subsection{Biosynthesis of FW-AgNPs}

The fresh and healthy leaves of $F$. wightiana were washed using distilled water (DW). Then the leaves were shade dried. After drying, the leaves were made into fine powder. Biosynthesis was carried out according to previous reports [36-40]. Ten gram of fine leaf powder was dissolved in $100 \mathrm{~mL}$ of DW and boiled for $30 \mathrm{~min}$ at temperature of 
$50{ }^{\circ} \mathrm{C}$ and then cooled to room temperature. Then the extract was filtrated using whatman filter paper and used for the biosynthesis of FW-AgNPs. $10 \mathrm{~mL}$ of leaf extract was added to $1 \mathrm{mM}$ of $\mathrm{AgNO}_{3}$ solution. The reaction mixture was vigorously shaken and incubated in the dark at room temperature for $4 \mathrm{~h}$. After $4 \mathrm{~h}$, observed the reaction mixture for color change from light yellow to dark brown.

\subsection{Characterization of FW-AgNPs}

UV-Vis analysis of the FW-AgNPs was carried out between 200 and $800 \mathrm{~nm}$ using UV-Vis double beam spectrometer. After the confirmation of synthesis, colloidal solution of FW-AgNPs was centrifuged at 15,000 rpm for $15 \mathrm{~min}$. Supernatant was discarded and the pellet obtained was dissolved in water and centrifugation was done again at $15,000 \mathrm{rpm}$ for $15 \mathrm{~min}$. The process was repeated three times and the final pellet obtained was dried and used for further characterization. FTIR analysis was carried out using bruker, alpha interferometer. FTIR spectrum was recorded between 500 and $4000 \mathrm{~cm}^{-1}$ to know the phytochemicals involved in synthesis (bioreduction) and capping (stabilization) of FW-AgNPs. EDX analysis of FWAgNPs was performed to reveal the presence of metallic silver (Oxford instruments, The business of Science). XRD analysis was carried out to know the crystal structure of FW-AgNPs (Rigaku, Tokyo, Japan) TEM analysis was done to know the size and shape of biosynthesized FW-AgNPs. Further selected area electron diffraction (SAED) pattern was also recorded using TEM. Average hydrodynamic size, Polydispersity index (PDI) and zeta potential value were determined by using DLS technique (Horiba Nanopartica).

\subsection{Antioxidant activity}

Antioxidant activity of the FW-AgNPs was evaluated by free radical scavenging assays including 1,1-Diphenyl2-picryl-hydrazyl (DPPH) and hydrogen peroxide $\left(\mathrm{H}_{2} \mathrm{O}_{2}\right)$ assays [40]. In DPPH assay, $1 \mathrm{mM}$ DPPH stock solution was prepared by adding $4 \mathrm{mg}$ of DPPH in $100 \mathrm{~mL}$ of methanol. $2 \mathrm{~mL}$ of DPPH stock solution was added to $1 \mathrm{~mL}$ of methanolic solution of FW-AgNPs containing different concentrations of FW-AgNPs $(20,40,60,80$ and $100 \mu \mathrm{g})$. Incubated this reaction mixture for $45 \mathrm{~min}$ at $518 \mathrm{~nm}$ in the dark at room temperature. After incubation the absorbance values were recorded at $518 \mathrm{~nm}$. In $\mathrm{H}_{2} \mathrm{O}_{2}$ assay, different concentrations of FW-AgNPs $(20,40,60,80$ and $100 \mu \mathrm{g})$ were added to $2 \mathrm{~mL}$ of $\mathrm{H}_{2} \mathrm{O}_{2}$ solution $(40 \mathrm{mM}$ ) prepared in phosphate buffer saline ( $\mathrm{pH} 7.4)$. Incubated this reaction mixture for $10 \mathrm{~min}$ and then absorbance values were recorded at $230 \mathrm{~nm}$. DPPH and $\mathrm{H}_{2} \mathrm{O}_{2}$ scavenging activity of the FW-AgNPs was calculated by formula \% Inhibition $=[($ Absorbance of control - Absorbance of sample $) /$ absorbance of control] $\times 100$. The concentration of inhibition of $50 \%$ free radicals $\left(I C_{50}\right)$ was calculated by linear regression coefficient $\left(R^{2}=0.9\right)$.

\subsection{Anticancer activity of FW-AgNPs}

Anticancer activity of the FW-AgNPs was checked by 3-(4,5-dimethylthiazol-2-yl)-2,5-diphenyl tetrazolium bromide (MTT) assay [56]. The cancer cell lines human ovarian carcinoma (SKOV3) and colon carcinoma (COLO205) were obtained from National centre for cellular sciences, Pune, India. Cells were cultured in Dulbecco's Modified Eagle's medium supplemented with $10 \% \mathrm{FBS}$, penicillin and streptomycin. Cells $\left(5 \times 10^{3}\right)$ were seeded in 96 -well plates and incubated for $12 \mathrm{~h}$ in the $\mathrm{CO}_{2}(5 \%)$ incubator. After $12 \mathrm{~h}$, different concentrations of FW-AgNPs were added to each well and incubated for $24 \mathrm{~h}$. After $24 \mathrm{~h}, 10 \mu \mathrm{L}$ of MTT ( $5 \mathrm{mg} / \mathrm{mL}$ in PBS) was added to each well and incubated further for $4 \mathrm{~h}$. After $4 \mathrm{~h}$, media and MTT were removed and formazan crystals were dissolved in $100 \mu \mathrm{L}$ of dimethyl sulfoxide and the absorption values were recorded at $570 \mathrm{~nm}$ using ELISA reader. The percentage inhibitions of cell viability were determined.

\section{Results and discussion}

In the present study, we report the biosynthesis of FWAgNPs using leaf extract of $F$. wightiana. The leaf extract acts as reducing agent which reduces the silver ions into nanosilver (AgNPs). After $4 \mathrm{~h}$ of incubation, the reaction mixture containing $1 \mathrm{mM}$ of $\mathrm{AgNO}_{3}$ and leaf extract was turned to dark brown color from light yellow (Fig. 1). The dark brown color indicated the biosynthesis of FW-AgNPs. The color change is the initial indication for the AgNPs'

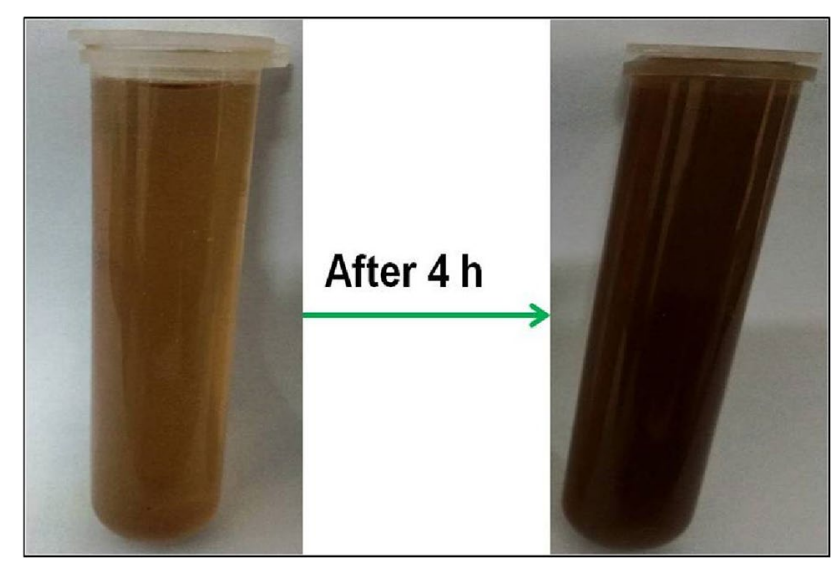

Fig. 1 Color change of reaction mixture from light yellow to dark brown indicated the biosynthesis of FW-AgNPs 


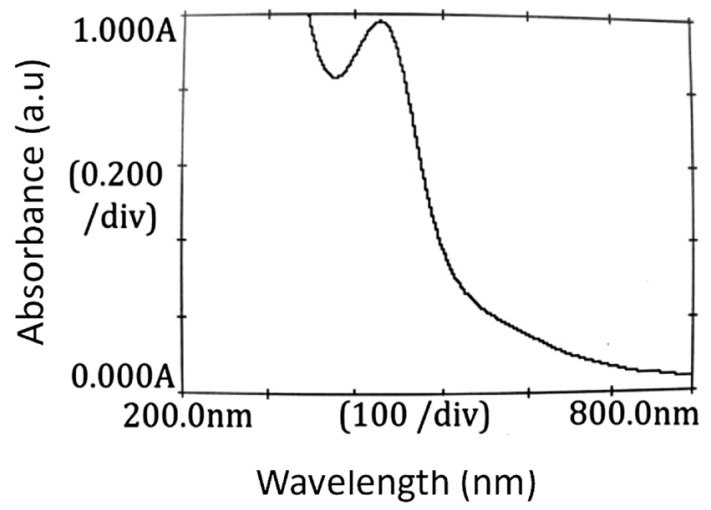

Fig. 2 UV-Vis analysis showed the characteristic SPR peak of FWAgNPs

synthesis [36-38]. Further the synthesis was confirmed by UV-Vis analysis of colloidal solution.

\subsection{UV-Vis analysis}

After visual detection of synthesis of FW-AgNPs, UV-Vis analysis of colloidal solution of FW-AgNPs showed absorption peak between 380 and $460 \mathrm{~nm}$ with maximum absorption at $428 \mathrm{~nm}$ (Fig. 2). UV-Vis absorption peak between 380 and $460 \mathrm{~nm}$ is the characteristic peak of FWAgNPs and it is due to surface plasmon resonance (SPR) and the peak is also called as SPR peak. SPR, a unique interaction of light where the free electrons of the metallic nanoparticles undergo oscillations with respect to the metal lattice in the presence of the oscillating electromagnetic field of the light. The broad applications of AgNPs are due to optical properties related with localized SPR phenomenon, surface bioconjugation with molecular probes, chemical surrounding, and adsorbed species in the surface as well as dielectric constant [57-59].

\subsection{FTIR analysis of FW-AgNPs}

FTIR analysis of FW-AgNPs showed the peaks at 3300.23, 2926.1, 1603.2, 1329.29, and $1036.84 \mathrm{~cm}^{-1}$ (Fig. 3). The peak at $3300.23 \mathrm{~cm}^{-1}$ related to hydroxyl group of the phenolic compounds and/or flavonoids and a short peak at $2926.1 \mathrm{~cm}^{-1}$ is related to the $\mathrm{C}-\mathrm{H}$ stretching vibrations of methylene group [36]. The peak at 1603.2 is related to the secondary amide of proteins, peak at 1329.29 is related to the aromatic group of polyphenolic compounds and flavonoids and the peak at 1036.84 is related to the carboxylic group of proteins and polypeptides [36-38]. FTIR spectrum clearly revealed that flavonoids and polyphenolic compounds involved in the bioreduction of silver to AgNPs $\left(\mathrm{Ag}^{+}-\mathrm{Ag}^{0}\right)$. While proteins involved in the stabilization of FW-AgNPs by capping them.

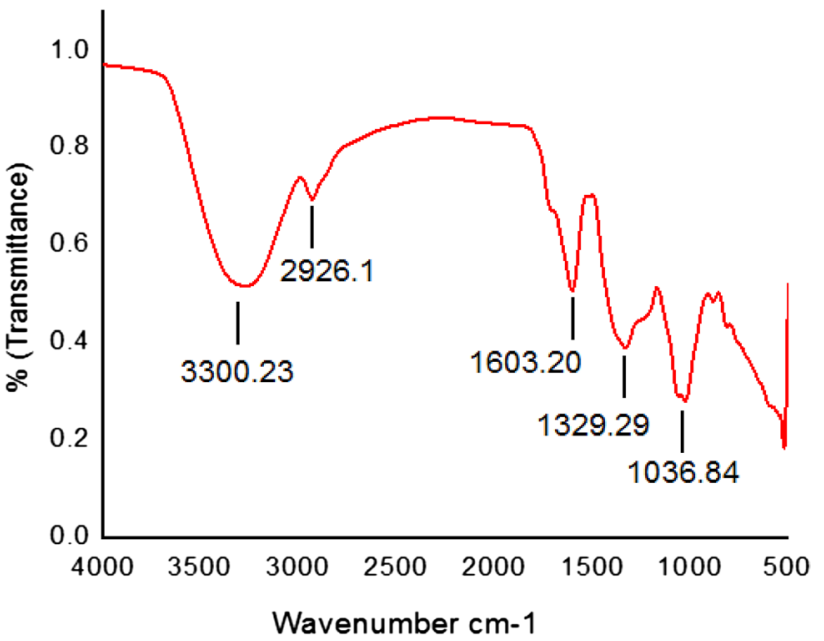

Fig. 3 FTIR spectrum of FW-AgNPs revealed the functional groups

\subsection{EDX analysis of FW-AgNPs}

EDX analysis (Fig. 4) was done to reveal the presence of metallic silver. EDX spectrum revealed the presence of metallic silver at $3 \mathrm{keV}$. The content (Weight percent) of elements were determined. The content of silver was found to be $41.0 \%$, Carbon (43.5\%), Oxygen (13.7\%), Potassium ( $0.6 \%)$, Chlorine (0.5\%), Calcium (0.4\%), Silicon $(0.3 \%)$ and Copper with negligible amounts. EDX results are supported by previous reports. AgNPs synthesized using Bridelia retusa leaf extract and Ipomoea digitata flower extract showed the strong signal of metallic silver at $3 \operatorname{keV}[60,61]$.

\subsection{XRD analysis of FW-AgNPs}

XRD analysis of FW-AgNPs was carried out to determine the crystalline nature. XRD pattern (Fig. 5) showed diffraction peaks at $2 \theta=38.4,43.8,63.8$, and 76.1 corresponding to (111) (200) (220) and (311) planes respectively. The peaks revealed that the synthesized FW-AgNPs are crystals with face centered cubic (FCC) shape. Further crystallite size $(\mathrm{nm})$ was calculated using the Scherrer equation. $\mathrm{D}=\mathrm{K} \lambda / \beta_{0.5} \cos \theta$. Where $\mathrm{d}$ indicates crystallite size $(\mathrm{nm}), \mathrm{K}$ indicates Scherrer constant $(0.94), \lambda$ wavelength $(1.54 \AA)$, $\beta_{0.5}$ indicates full width at half maximum length $\left(0.611^{\circ}\right)$ and $\theta$ indicates Bragg's angle in the radian. According to this equation the crystallite size in the present study was calculated as $17.34 \mathrm{~nm}$. XRD results in the present study are in line with previous reports. Vinayagam et al. [60] reported that $B$. retusa leaf synthesized AgNPs are crystalline in nature with FCC structure and crystalline size was calculated as $16.21 \mathrm{~nm}$. Similar type of results was also observed for the AgNPs synthesized using fruit extract of 
Fig. 4 EDX analysis of FWAgNPs shows sharp metallic silver peak at $3 \mathrm{keV}$

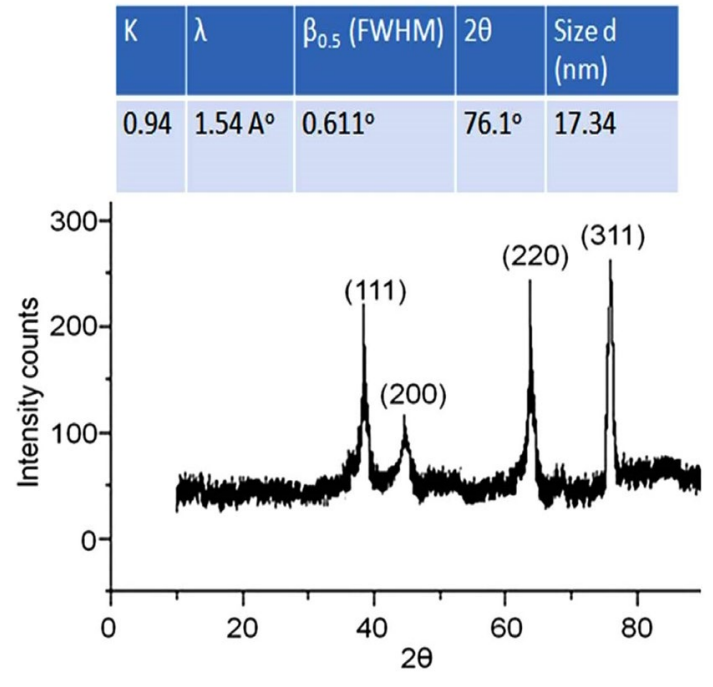

Fig. 5 XRD pattern of FW-AgNPs

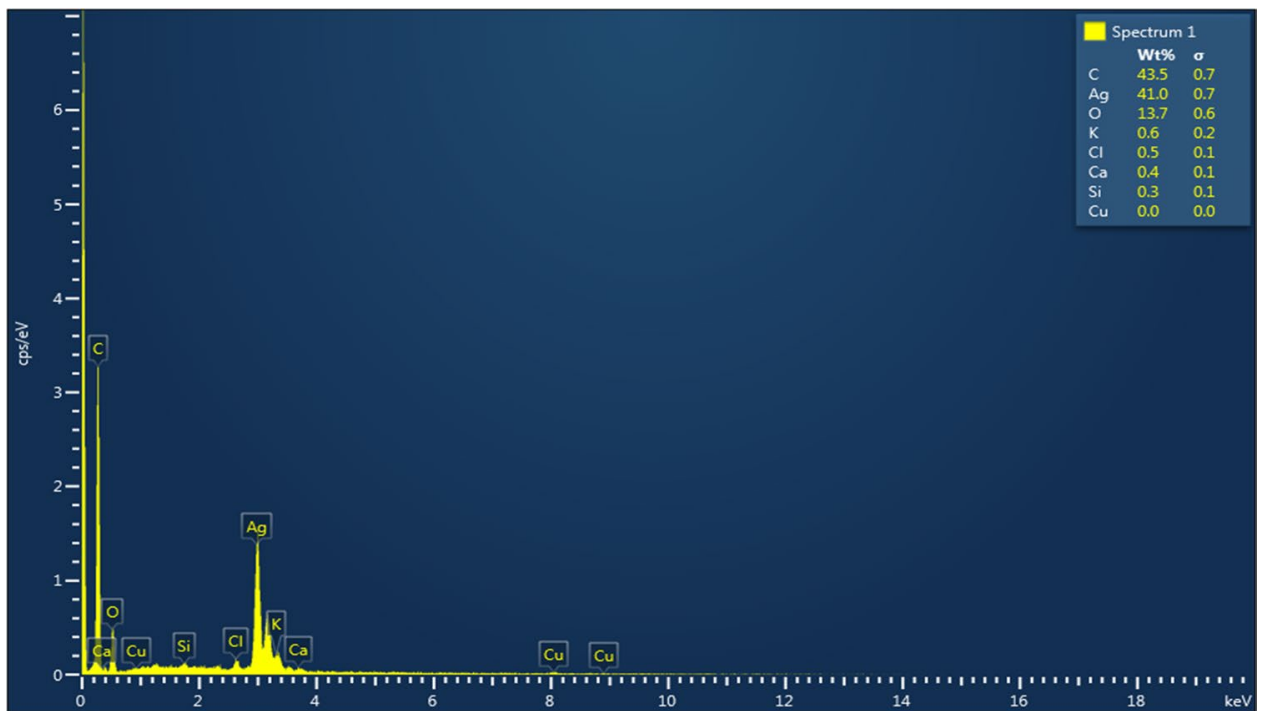

B. retusa. Bridelia retusa fruit synthesized AgNPs were FCC crystals with $22.48 \mathrm{~nm}$ size [62].

\subsection{TEM analysis of FW-AgNPs}

TEM analysis revealed that the biosynthesized FW-AgNPs are spherical in shape with sizes ranging between 20 and $40 \mathrm{~nm}$ (Fig. 6a). TEM analysis showed that FW-AgNPs are not aggregated and polydispersed. Further TEM was also used to reveal the SAED pattern. SAED pattern (Fig. 6b) revealed four diffraction peaks belonged to (111) (200) (220) and (311) planes. XRD and SAED results are in agreement with each other and showed that biosynthesized FW-AgNPs are FCC crystals. TEM results are in consistence with previous reports. AgNPs synthesized using Gymnema sylvestre, Centella asiatica and Melia dubia are spherical in shape with sizes ranging below $50 \mathrm{~nm}$ with FCC structure [36-41].
Fig. 6 a TEM micrograph of FW-AgNPs and $\mathbf{b}$ SAED pattern of FW-AgNPs

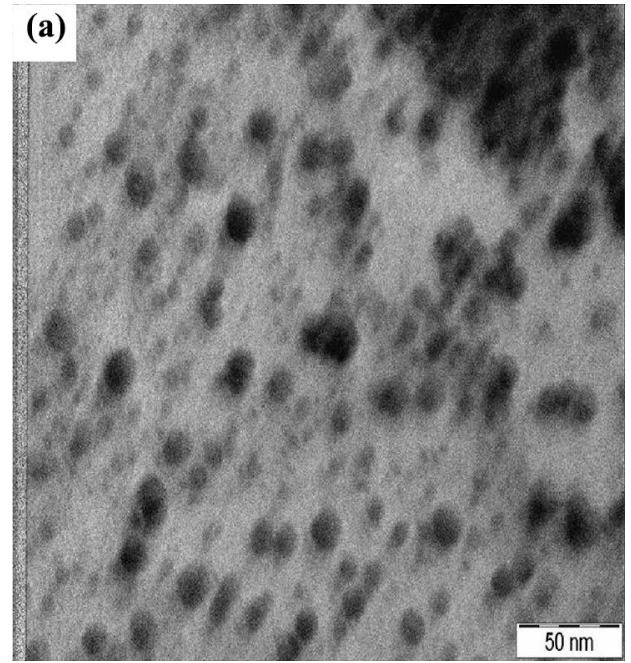

(b)

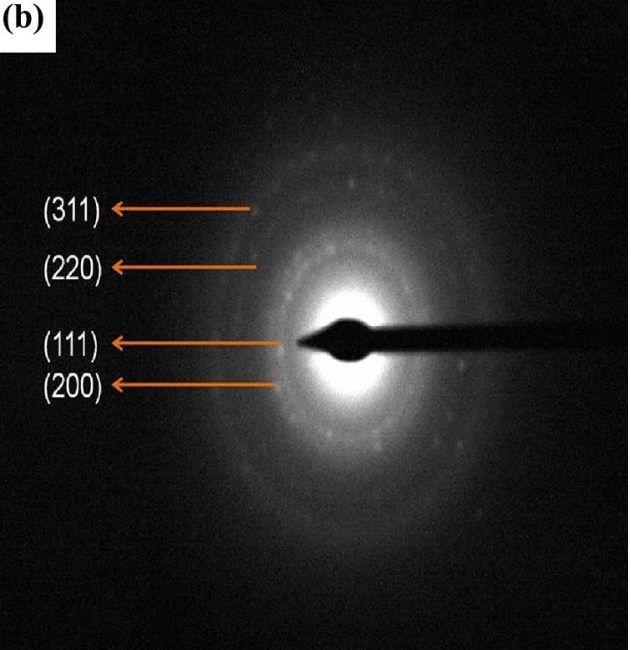

SN Applied Sciences A SPRINGER NatURE journa 


\subsection{DLS analysis of FW-AgNPs}

In the present study the hydrodynamic size of FW-AgNPs was found to be $47.6 \mathrm{~nm}$ and the PDI of AgNPs was found to be 4.5 (Fig. 7). The DLS results revealed the polydispersed nature without any agglomeration of AgNPs. DLS studies also revealed zeta potential value of the FW-AgNPs was found to be $-25.3 \mathrm{mV}$ (Fig. 8). This high negative surface charge indicates the stability of synthesized FWAgNPs without any agglomeration. The non-agglomeration is due to the fact that the synthesized FW-AgNPs are capped by proteins of the leaf extract. The capped proteins further give negative charge on the surface of nanoparticles. Thus the DLS studies in this investigation report the formation of small sized, polydispersed, non-agglomerated and stabilized AgNPs. The results are consistent with previous reports. Average hydrodynamic size, PDI and zeta potential value of Ipomoea digitata flower extract synthesized AgNPs were found to be $111 \mathrm{~nm}, 0.197$ and $-25.1 \mathrm{mV}$ respectively [61]. Average hydrodynamic size,
PDI and zeta potential value of AgNPs synthesized using leaf extract of Spondias dulcis were found to be $59.66 \mathrm{~nm}$, 0.187 and $-15.7 \mathrm{mV}$ respectively [63].

\subsection{Antioxidant activity of FW-AgNPs}

Antioxidant activity of FW-AgNPs was evaluated by DPPH and $\mathrm{H}_{2} \mathrm{O}_{2}$ free radical scavenging assays. FW-AgNPs showed concentration dependant scavenging activity against both DPPH and $\mathrm{H}_{2} \mathrm{O}_{2}$ free radicals. Increase in the concentration of FW-AgNPs from 25 to $100 \mu \mathrm{g} / \mathrm{mL}$ increased the DPPH scavenging activity from 22.52 to $65.35 \%$ (Fig. 9). Similarly, increase in concentration from 25 to $100 \mu \mathrm{g} / \mathrm{mL}$ of FW-AgNPs showed increased inhibition of $\mathrm{H}_{2} \mathrm{O}_{2}$ radicals from 21.20 to $58.4 \%$. $\mathrm{IC}_{50}$ values of the $\mathrm{FW}$ AgNPs against DPPH and $\mathrm{H}_{2} \mathrm{O}_{2}$ radicals were respectively found to be 71.96 and $80.59 \mu \mathrm{g} / \mathrm{mL}$. The inhibition percentages and $\mathrm{IC}_{50}$ values indicated that FW-AgNPs effectively showed antioxidant activity. The antioxidant activity of AgNPs was due to flavonoids, polyphenols and proteins
Fig. 7 DLS studies show average hydrodynamic size and PDI of FW-AgNPs

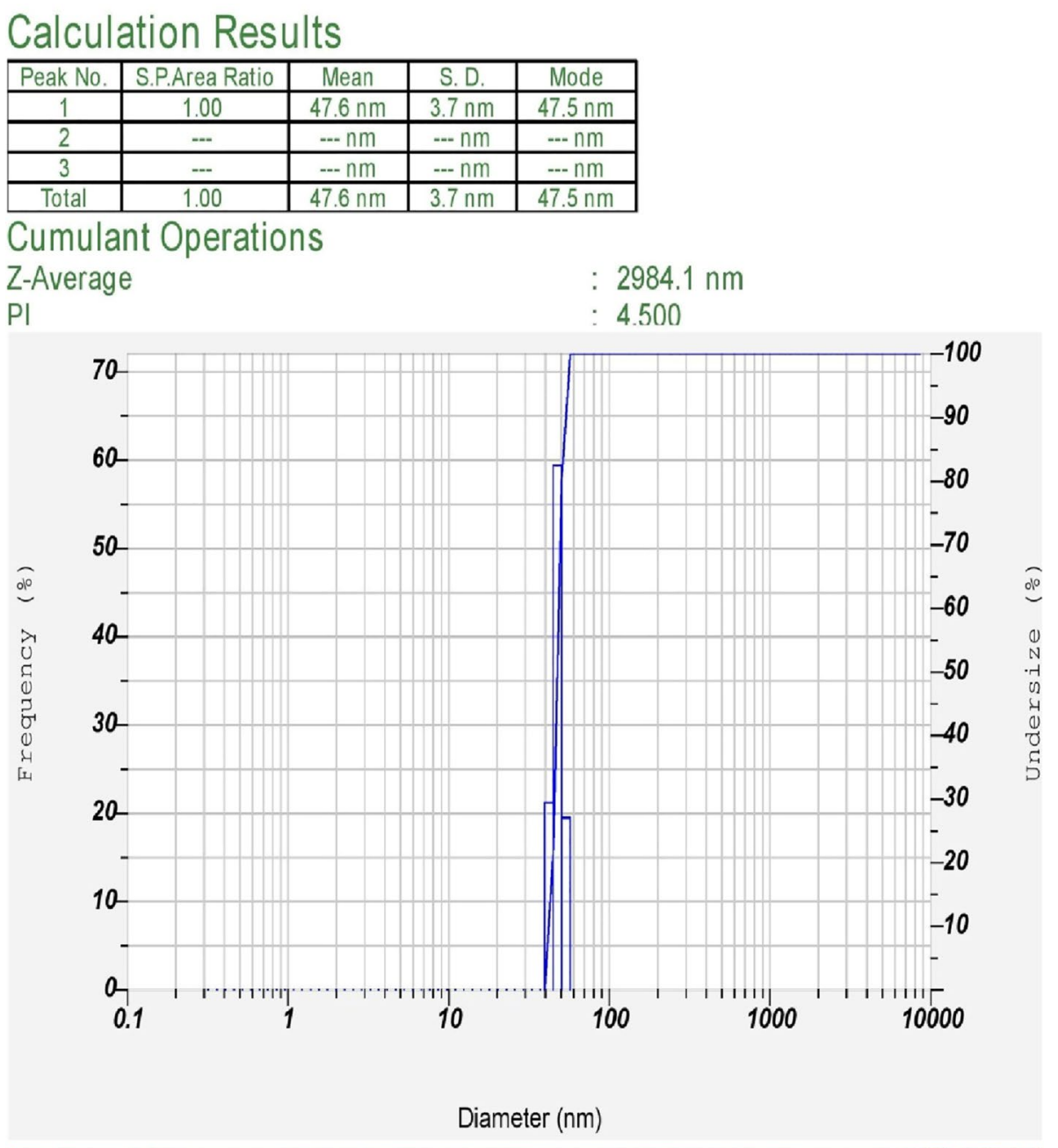

HORIEA 
Fig. 8 DLS studies show zeta potential value of FW-AgNPs
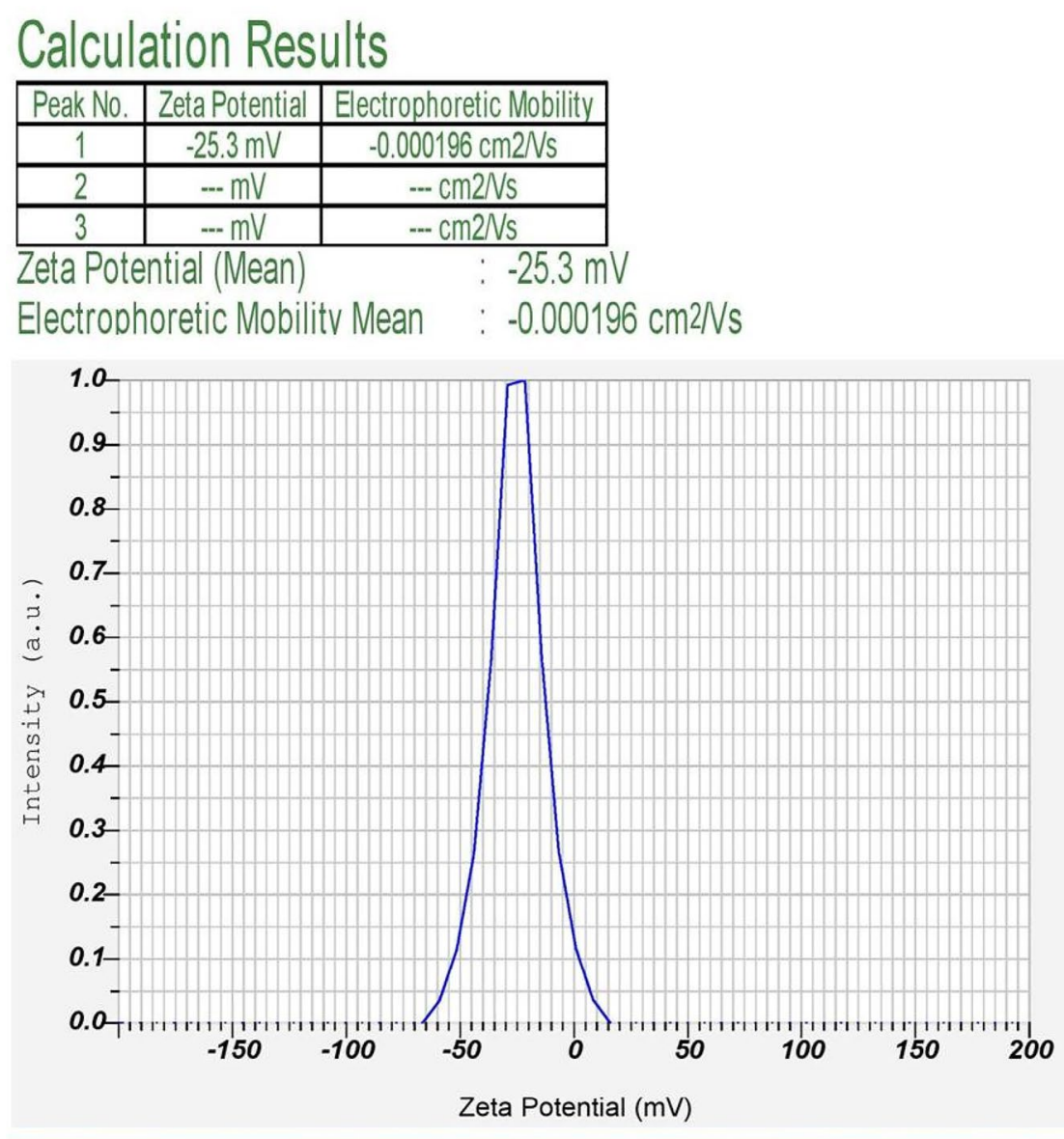

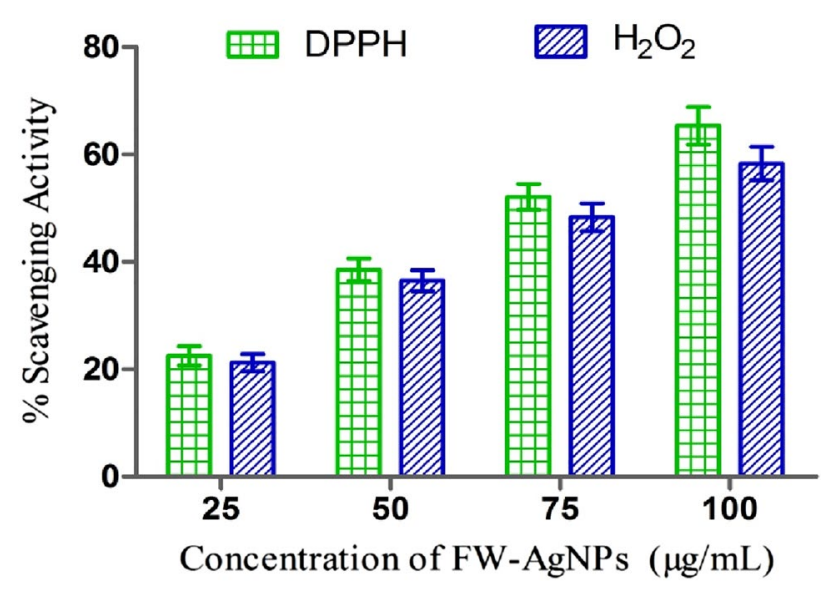

Fig. 9 Free radical scavenging activity of FW-AgNPs against DPPH and $\mathrm{H}_{2} \mathrm{O}_{2}$ radicals

involved in the bioreduction of stabilization of FW-AgNPs [64]. The imbalance between antioxidants and oxidative system results in the production of oxidative stress. Oxidative stress is associated with different disorders including aging, cancer, diabetes, hypertension, atherosclerosis, cardiovascular and neurodegenerative disorders [65]. Hence it is necessary to remediate oxidative stress with antioxidants. Due to side effects of synthetic antioxidants, scientists focus on natural antioxidants. The phytochemicals such as polyphenols and flavonoids were proved to be effective antioxidants [66]. In this study, FTIR analysis revealed the participation of polyphenols and flavonoids in the bioreduction and stabilization of FW-AgNPs. The DPPH and $\mathrm{H}_{2} \mathrm{O}_{2}$ radical scavenging activity of FW-AgNPs in the present study provides the evidence for the AgNPs as antioxidants. The results are supported by previous reports for the antioxidant activity of biosynthesized AgNPs using different plants. AgNPs synthesized using seed hull extract of Vigna mungo exhibited effective DPPH radical scavenging activity with $75.53 \%$ of maximum inhibition [67]. Bauhinia variegata flower extract synthesized AgNPs showed DPPH radical scavenging activity with $\mathrm{IC}_{50}$ value of $4.64 \mu \mathrm{g} / \mathrm{mL}$ [68]. AgNPs synthesized using Chaenomeles sinensis fruit extract mediated AgNPs showed effective DPPH scavenging activity [69]. Antioxidant activity is the important property for AgNPs as they will be used for different biological, neutraceutical and pharmaceutical purposes. 


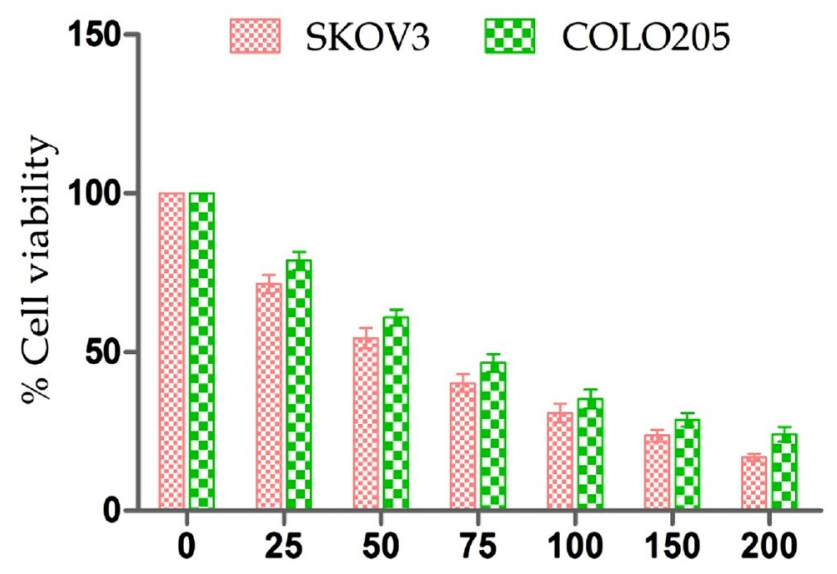

Concentration of FW-AgNPs $(\mu \mathrm{g} / \mathrm{mL})$

Fig. 10 Anticancer activity of FW-AgNPs against SKOV3 and COLO205 cells

\subsection{Anticancer activity of FW-AgNPs}

Anticancer activity of the FW-AgNPs was checked against SKOV3 and COLO205. FW-AgNPs showed dosage dependant anticancer activity against both SKOV3 and COLO205 cells (Fig. 10). Increase in the dosage of FW-AgNPs decreased the percentage of cell viability of both SKOV3 and COLO205 cells. The increase in the concentration of FW-AgNPs from 25 to $100 \mu \mathrm{g} / \mathrm{mL}$ decreases the cell viability significantly, but further increase in the concentration could not show effective cytotoxicity. In this study, FWAgNPs exhibited maximum inhibition of 83.2 and $75.9 \%$ respectively against SKOV3 and COLO205 at the highest concentration of $200 \mu \mathrm{g} / \mathrm{mL}$ of FW-AgNPs. IC ${ }_{50}$ values were determined as 63.2 and $68.1 \mu \mathrm{g} / \mathrm{mL}$ respectively against SKOV3 and COLO205. The results revealed that SKOV3 cells are more susceptible to FW-AgNPs compared to COLO205. The anticancer activity could due to two important properties; smaller size facilitated them to permeate the cancer cells and tumor matrix very effectively $[39,52]$, and the flavonoids, and polyphenols involved in their synthesis might impart cytotoxicity for nanoparticles against different cancer cell lines [39].

\section{Conclusions}

The present study report the successful synthesis of FWAgNPs using the aqueous leaf extract of $F$. wightiana. Leaf extract acts as both reducing and capping agent. Biosynthesized FW-AgNPs are FCC crystals, 20-40 nm in size, spherical shaped, polydispersed, non-agglomerated and stable with high negative surface charge. FTIR studies indicated that polyphenols and flavonoids involved in the biosynthesis of FW-AgNPs, while proteins involved in the stabilization of FW-AgNPs by capping around them. FW-AgNPs function as 2-in-1 system which exhibited both antioxidant and anticancer activities.

Authors' contributions All the work was done under the supervision of Prof.T. Vijaya. N. Vasudeva Reddy carried out synthesis, characterization studies and manuscript preparation. Dr. Murali carried out characterization and anticancer activity studies. Dr. Pragathi did antioxidant activity studies. Dr. KVS helped for zeta potential characterization. Dr. Sivasankar helped for the correction of the manuscript.

\section{Compliance with ethical standards}

Conflict of interest All the authors declared that they are no conflicts of interest

Human and animal rights No animals were used for the present study Consent for publication All the authors approved and consent for publication

\section{References}

1. Ravindran A, Chandran P, Khan SS (2013) Biofunctionalized silver nanoparticles: advances and prospects. Colloids Surf B Biointerfaces 105:342-352. https://doi.org/10.1016/j.colsu rfb.2012.07.036

2. Mukherjee S, Chowdhury D, Kotcherlakota R et al (2014) Potential theranostics application of bio-synthesized silver nanoparticles (4-in-1 system). Theranostics 4:316-335. https://doi. org/10.7150/thno.7819

3. Gonzalez C, Rosas-Hernandez H, Ramirez-Lee MA et al (2016) Role of silver nanoparticles (AgNPs) on the cardiovascular system. Arch Toxicol 90:493-511. https://doi.org/10.1007/s0020 4-014-1447-8

4. Gonzalez-Carter DA, Bey FL, Pakatip R et al (2017) Silver nanoparticles reduce brain inflammation and related neurotoxicity through induction of H2S-synthesizing enzymes. Sci Rep 7:42871. https://doi.org/10.1038/srep42871

5. Prabhu S, Vinodhini S, Elanchezhiyan C, Rajeswari D (2018) Evaluation of antidiabetic activity of biologically synthesized silver nanoparticles using Pouteria sapota in streptozotocin-induced diabetic rats. J Diabetes 10:28-42. https://doi. org/10.1111/1753-0407.12554

6. Vinoth S, Shankar SG, Gurusaravanan P et al (2019) Anti-larvicidal activity of silver nanoparticles synthesized from Sargassum polycystum against mosquito vectors. J Clust Sci 30:171-180. https://doi.org/10.1007/s10876-018-1473-4

7. Adil MA, Emrah SA, Malahat B et al (2011) Antileishmanial effect of silver nanoparticles and their enhanced antiparasitic activity under ultraviolet light. Int J Nanomedicine 6:2705-2714. https ://doi.org/10.2147/IJN.S23883

8. Murugan K, Benelli G, Ayyappan S et al (2015) Toxicity of seaweed-synthesized silver nanoparticles against the filariasis vector Culex quinquefasciatus and its impact on predation efficiency of the cyclopoid crustacean Mesocyclops longisetus. Parasitol Res 114:2243-2253. https://doi.org/10.1007/s00436-015-4417-z

9. Jalal M, Ansari MA, Alzohairy MA et al (2019) Anticandidal activity of biosynthesized silver nanoparticles: effect on growth, cell 
morphology, and key virulence attributes of Candida species. Int J Nanomedicine 14:4667-4679. https://doi.org/10.2147/IJN. S210449

10. Ahad M, Eivazzadeh-Keihan R, Paria P et al (2017) Nanomaterial based biosensors for detection of pathogenic virus. Trends Anal Chem 97:445-457. https://doi.org/10.1016/j.trac.2017.10.005

11. Khater M, de la Escosura-Muñiz A, Merkoçi A (2017) Biosensors for plant pathogen detection. Biosens Bioelectron 93:72-86. https://doi.org/10.1016/j.bios.2016.09.091

12. Jasmina V, Marisa M, Chung-Ming C, Jaffrezic-Renault N (2017) Advanced biosensors for detection of pathogens related to livestock and poultry. Vet Res 48:11. https://doi.org/10.1186/s1356 7-017-0418-5

13. Xia B, Fang $H$, Lidong $L$ (2014) Metal-enhanced fluorescence using aggregated silver nanoparticles. Colloids Surf A Physicochem Eng Asp 444:9-14. https://doi.org/10.1016/j.colsu rfa.2013.12.029

14. Krishanu R, Joseph RL (2013) Metal-enhanced fluorescence lifetime imaging and spectroscopy on a modified SERS substrate. J Phys Chem C 117:15790-15797. https://doi.org/10.1021/jp404 590j

15. Vidhu VK, Philip D (2014) Catalytic degradation of organic dyes using biosynthesized silver nanoparticles. Micron 56:54-62. https://doi.org/10.1016/j.micron.2013.10.006

16. Kamal T, Khan MSJ, Khan SB et al (2020) Silver nanoparticles embedded in gelatin biopolymer hydrogel as catalyst for reductive degradation of pollutants. J Polym Environ 28:399-410. https://doi.org/10.1007/s10924-019-01615-8

17. Manohar AB, Bhalchandra MB (2015) Silver nanoparticles: synthesis, characterization and their application as a sustainable catalyst for organic transformations. Curr Org Chem 19:708-727. https://doi.org/10.2174/1385272819666150207001154

18. Huan C, Clinton FB, Sean JE et al (2010) Silver nanoparticle-catalyzed diels- alder cycloadditions of 2'-hydroxychalcones. J Am Chem Soc 132:7514-7518. https://doi.org/10.1021/ja102482b

19. Robert BR, Tatiana Z, Angela B et al (2016) Potential environmental impacts and antimicrobial efficacy of silver- and nanosilvercontaining textiles. Environ Sci Technol 50:4018-4026. https:// doi.org/10.1021/acs.est.5b06043

20. Patra JK, Gouda S (2013) Application of nanotechnology in textile engineering: an overview. J Eng Technol Res 5:104-111. https://doi.org/10.5897/jetr2013-0309

21. Kumar A, Vemula P, Ajayan P et al (2008) Silver nanoparticle embedded antimicrobial paints based on vegetable oil. Nat Mater 7:236-241. https://doi.org/10.1038/nmat2099

22. Hasan A, Morshed M, Memic A et al (2018) Nanoparticles in tissue engineering: applications, challenges and prospects. Int J Nanomedicine 13:5637-5655. https://doi.org/10.2147/IJN. S153758

23. Carbone M, Domenica TD, Sabbatella G, Antiochia R (2016) Silver nanoparticles in polymeric matrices for fresh food packaging. J King Saud Univ 28:273-279. https://doi.org/10.1016/j.jksus .2016.05.004

24. Rigo R, Ferroni L, Tocco I (2013) Active silver nanoparticles for wound healing. Int J Mol Sci 14:4817-4840. https://doi. org/10.3390/ijms14034817

25. Kunal A, Amit R (2018) Silver nanoparticles market size by application (Healthcare \& Lifesciences, Textiles, Electronics \& IT, Food \& Beverage), Industry Analysis Report, Regional Outlook, Growth Potential, Price Trends, Competitive Market Share \& Forecast, 2018-2024. Global market insights. https://www. gminsights.com/industry-analysis/silver-nanoparticles-marke t. Accessed 12 July 2018

26. Togashi T, Saito K, Matsuda Y et al (2014) Synthesis of waterdispersible silver nanoparticles by thermal decomposition of water-soluble silver oxalate precursors. J Nanosci Nanotechnol 14:6022-6027. https://doi.org/10.1166/jnn.2014.8739

27. Pyatenko A, Shimokawa K, Yamaguchi M et al (2004) Synthesis of silver nanoparticles by laser ablation in pure water. Appl Phys A 79:803-806. https://doi.org/10.1007/s0033 9-004-2841-5

28. Rodriguez-Sanchez L, Blanco MC, Lopez-Quintela MA (2000) Electrochemical synthesis of silver nanoparticles. J Phys Chem B 104:9683-9688. https://doi.org/10.1021/jp001761r

29. Maretti L, Billone PS, Liu Y, Scaiano JC (2009) Facile photochemical synthesis and characterization of highly fluorescent silver nanoparticles. J Am Chem Soc 131:13972-13980. https://doi. org/10.1021/ja900201k

30. Talebi J, Rouein H, Askari S (2010) Sonochemical synthesis of silver nanoparticles in Y-zeolite substrate. J Mater Sci 45:33183324. https://doi.org/10.1007/s10853-010-4349-z

31. Madhu KR, Lakshmeesha RB, Asha S et al (2015) Gamma radiation assisted biosynthesis of silver nanoparticles and their characterization. Adv Mater Lett 6:1088-1093. https://doi. org/10.5185/amlett.2015.6002

32. Byeon JH, Kim YW (2012) A novel polyol method to synthesize colloidal silver nanoparticles by ultrasonic irradiation. Ultrason Sonochem 19:209-215. https://doi.org/10.1016/j.ultso nch.2011.06.004

33. Bouazza S, Alonzo V, Hauchard D (2009) Synthesis and characterization of Ag nanoparticles-polyaniline composite powder material. Synth Metals 159:1612-1619. https://doi.org/10.1016/j. synthmet.2009.04.025

34. Ramajo L, Parra R, Reboredo M, Castro M (2009) Preparation of amine coated silver nanoparticles using triethylenetetraamine. J Chem Soc 121:83-87. https://doi.org/10.1007/s1203 9-009-0009-8

35. Jensen TR, Malinsky MD, Haynes CL, Duyne RPV (2000) Nanosphere lithography: tunable localized surface plasmon resonance spectra of silver nanoparticles. J Phys Chem B 104:1054910556. https://doi.org/10.1021/jp002435e

36. Reddy NV, Venkata SK, Latha D et al (2016) Biogenic silver nanoparticles: efficient and effective antifungal agents. Appl Nanosci 6:475-484. https://doi.org/10.1007/s13204-015-0463-1

37. Reddy NV, Venkata SK, Nagam V et al (2015) First report of biomimetic synthesis of silver nanoparticles using aqueous callus extract of Centella asiatica and their antimicrobial activity. Appl Nanosci 5:801-807. https://doi.org/10.1007/s13204-014-0374-6

38. Reddy NV, Venkata SK, Ghosh SB et al (2014) Biofabrication of silver nanoparticles using aqueous leaf extract of Melia dubia, characterization and antifungal activity. Int J Pharm Pharm Sci 6:298-300

39. Murali SB, Reddy NV, Latha D et al (2018) Potential anticancer activity of biogenic silver nanoparticles using leaf extract of Rhynchosia suaveolens: an insight into the mechanism. Artif Cells Nanomed Biotechnol 46:104-114. https://doi. org/10.1080/21691401.2017.1414824

40. Subramanian R, Subramanian P, Raj V (2013) Antioxidant activity of the stem bark of Shorea roxburghii and its silver reducing power. Springerplus 2:28. https://doi. org/10.1186/2193-1801-2-28

41. Das D, Ghosh R, Mandal $P$ (2019) Biogenic synthesis of silver nanoparticles using S1 genotype of Morus alba leaf extract: characterization, antimicrobial and antioxidant potential assessment. SN Appl Sci 1:498. https://doi.org/10.1007/s42452-019-0527-z

42. Ananda AP, Krishnamurthy NB, Savitha KR, Nagendra BS (2019) Biogenic synthesis of silver nanoparticles using Priva cordifolia leaf extract (PC@AgNPs) a potent antioxidant, antibacterial and catalytic activity. SN Appl Sci 1:800. https://doi.org/10.1007/ s42452-019-0818-4 
43. Venkata SK, Rao YS, Aparna SG et al (2013) Simple and rapid biosynthesis of stable silver nanoparticles using dried leaves of Catharanthus roseus Linn. G. Donn and its anti microbial activity. Colloids Surf B Biointerfaces 105:194-198. https://doi. org/10.1016/j.colsurfb.2013.01.003

44. Venkata SK, Aparna SG, Rao YS et al (2014) Biofabrication of silver nanoparticles using Andrographis paniculata. Eur J Med Chem 73:135-140. https://doi.org/10.1016/j.ejmech.2013.12.004

45. Bharathi D, Vasantharaj S, Bhuvaneshwari V (2018) Green synthesis of silver nanoparticles using Cordia dichotoma fruit extract and its enhanced antibacterial, anti-biofilm and photo catalytic activity. Mater Res Exp 5:055404. https://doi.org/10.1088/20531591/aac2eF

46. Peter AT, Sivagami S, Akkini DT et al (2012) Biogenic synthesis of silver nanoparticles by leaf extract of Cassia angustifolia. Adv Nat Sci Nanosci Nanotechnol 3:045006. https://doi. org/10.1088/2043-6262/3/4/045006

47. Baghani M, Es-haghi Ali (2019) Characterization of silver nanoparticles biosynthesized using Amaranthus cruentus. Bioinsp Biomim Nanobiomater 2019:1-8. https://doi.org/10.1680/jbibn .18 .00051

48. Lateef A, Azeez MA, Asafa TB et al (2016) Biogenic synthesis of silver nanoparticles using a pod extract of Cola nitida: antibacterial and antioxidant activities and application as a paint additive. J Taibah Univ Sci 10:551-562. https://doi.org/10.1016/j.jtusc i. 2015.10 .010

49. Shruti N, Veena A (2019) Fabrication of silver nanoparticles using Arnebia hispidissima (Lehm.) A. DC. root extract and unraveling their potential biomedical applications. Artif Cells Nanomed Biotechnol 47:166-180. https://doi.org/10.1080/21691 401.2018.1548469

50. Lateef A, Bolaji IF, Suliat MO et al (2018) Characterization, antimicrobial, antioxidant, and anticoagulant activities of silver nanoparticles synthesized from Petiveria alliacea $\mathrm{L}$. leaf extract. Prep Biochem Biotechnol 48:646-652. https://doi.org/10.1080/10826 068.2018.1479864

51. Adebayo AE, Oke AM, Lateef $A$ et al (2019) Biosynthesis of silver, gold and silver-gold alloy nanoparticles using Persea americana fruit peel aqueous extract for their biomedical properties. Nanotechnol Environ Eng 4:13. https://doi.org/10.1007/s4120 4-019-0060-8

52. Khateef $\mathrm{R}$, Khadri $\mathrm{H}$, Ahmad $\mathrm{A}$ et al (2019) Potential in vitro antibreast cancer activity of green-synthesized silver nanoparticles preparation against human MCF-7 cell-lines. Adv Nat Sci Nanosci Nanotechnol 10:045012. https://doi.org/10.1088/20436254/ab47ff

53. Nayak S, Sajankila SP, Rao CV et al (2019) Biogenic synthesis of silver nanoparticles using Jatropha curcas seed cake extract and characterization: evaluation of its antibacterial activity. Energy Sources Part A Recovery Util Environ Effects. https://doi. org/10.1080/15567036.2019.1632394

54. Sanjappa M (1992) Legumes of India. Dehra Dun. Bishen singh Mahendra

55. Sudhakar Y, Padmaja Y, Jayaveera KN, Reddy AV (2011) Investigation of analgesic and anti-inflammatory potential of ethanolic extract of Flemingia wightiana. Int J Pharm Pharm Sci 3:229-233

56. Mosmann T (1983) Rapid colorimetric assay for cellular growth and survival: application to proliferation and cytotoxicity assays. J Immunol Methods 65:55-63
57. Kelly KL, Coronando E, Zhao LL, Schatz GC (2002) The optical properties of metal nanoparticles: the influence of size, shape and dielectric environment. J Phys Chem B 107:668-677. https ://doi.org/10.1021/jp026731y

58. Kreibig U, Vollmer M (1995) Optical properties of metal clusters. Springer, Berlin, pp 483-525

59. Feiner LF (2006) Nanoelectronics: crossing boundaries and borders. Nat Nano 1:91-92

60. Vinayagam R, Varadavenkatesan T, Selvaraj R (2018) Green synthesis, structural characterization, and catalytic activity of silver nanoparticles stabilized with Bridelia retusa leaf extract. Green Proc Synth 7:30-37. https://doi.org/10.1515/gps-2016-0236

61. Varadavenkatesan T, Selvaraj R, Vinayagam R (2019) Dye degradation and antibacterial activity of green synthesized silver nanoparticles using Ipomoea digitata Linn. flower extract. Int J Environ Sci Technol 16:2395-2404. https://doi.org/10.1007/ s13762-018-1850-4

62. Varadavenkatesan T, Selvaraj R, Vinayagam R (2017) Evaluation of the anticoagulant and catalytic activities of the Bridelia retusa fruit extract-functionalized silver nanoparticles. J Cluster Sci 28:2919-2932. https://doi.org/10.1007/s10876-017-1270-5

63. Yadav P, Manjunath H, Selvaraj R (2018) Antibacterial and dye degradation potential of zero-valent silver nanoparticles synthesized using the leaf extract of Spondias dulcis. IET Nanobiotechnol 13:84-89. https://doi.org/10.1049/iet-nbt.2018.5058

64. Abdel-Aziz MS, Shaheen MS, El-Nekeety AA, Abdel-Wahhab Mosaad A (2014) Antioxidant and antibacterial activity of silver nanoparticles biosynthesized using Chenopodium murale leaf extract. J Saudi Chem Soc 18:356-363. https://doi.org/10.1016/j. jscs.2013.09.011

65. Birben E, Sahiner UM, Sackesen C, Erzurum S, Kalayci O (2012) Oxidative stress and antioxidant defense. World Aller Organ J 5:9-19. https://doi.org/10.1097/WOX.0b013e3182439613

66. Xu D-P, Li Y, Meng X, Zhou T, Zhou Y, Zheng J, Zhang J-J, Li H-B (2017) Natural antioxidants in foods and medicinal plants: extraction, assessment and resources. Int J Mol Sci 18:96. https ://doi.org/10.3390/ijms18010096

67. Varadavenkatesan T, Vinayagam R, Selvaraj R (2017) Structural characterization of silver nanoparticles phyto-mediated by a plant waste, seed hull of Vigna mungo and their biological applications. J Mol Struct 1147:629-635. https://doi.org/10.1016/j. molstruc.2017.07.002

68. Johnson P, Krishnan V, Loganathan C et al (2018) Rapid biosynthesis of Bauhinia variegata flower extract mediated silver nanoparticles: an effective antioxidant scavenger and a-amylase inhibitor. Artif cells Nanomed Biotechnol 46:1488-1494. https ://doi.org/10.1080/21691401.2017.1374283

69. Oh KH, Soshnikova V, Markus J, Kim YJ et al (2018) Biosynthesized gold and silver nanoparticles by aqueous fruit extract of Chaenomeles sinensis and screening of their biomedical activities. Artif cells Nanomed Biotechnol 46:599-606. https://doi. org/10.1080/21691401.2017.1332636

Publisher's Note Springer Nature remains neutral with regard to jurisdictional claims in published maps and institutional affiliations. 